\title{
IMPORTÂNCIA DA MONITORIA NA DISCIPLINA DE QUÍMICA EXPERIMENTAL APLICADA À ENGENHARIA: UM ESTUDO DE CASO EM TUCURUÍ/PA
}

DOI: 10.37702/2175-957X.COBENGE.2021.3703

Marcos Paulo Santos Nunes - marcossn23@gmail.com

Universidade Federal do Pará

Pass. 24 de dezembro 102

66077-720 - Belém - PA

João Alcebíades Cardoso e Silva - joao.alcebiarde@gmail.com

Universidade Federal do Pará

Rua Aziz Mutran 1729

68503-650 - Marabá - PA

Larissa Nunes Bezerra - laris.nunes.In@gmail.com

Universidade Federal do Pará

R. Gov Magalhães Barata 1726

68371-057 - Altamira - PA

KARYME do Socorro de Souza Vilhena - karyme@ufpa.br

Universidade Federal do Pará

Rua trombetas 13

68455-747 - Tucuruí - PA

Grazielle Tigre de Souza - grazielletigre@ufpa.br

Universidade Federal do Pará

Travessa W02 331

68464-000 - Tucuruí - PA

Resumo: A disciplina de Química Experimental, dentro da formação do aluno de engenharia, apresenta uma significativa importância aliando a teoria e a prática. Desta maneira, o presente trabalho tem como objetivo enfatizar a contribuição da monitoria nesta componente curricular do curso de Engenharia Civil da UFPA Campus Tucuruí. Neste contexto, desenvolveu-se uma análise comparativa dos conceitos obtidos pelos discentes da turma 2018.2 e 2019.2. Com base nos 
resultados analisados, destaca-se que os discentes da turma 2019.2 alcançaram melhores desempenhos visto que contaram com o auxílio de dois monitores durante as aulas, como resultado $34,8 \%$ dos alunos atingiram notas máximas e não houve nenhuma reprovação, já na turma 2018.2, havendo somente um monitor, apenas $8,7 \%$ dos alunos tiraram o conceito máximo na disciplina e aproximadamente $11 \%$ foram reprovados. Portanto, pode-se enfatizar a importância da monitoria para auxiliar no desempenho e sucesso dos discentes da turma, bem como proporcionar aos monitores a possibilidade de desenvolver habilidades no processo de ensino-aprendizagem, contribuindo para sua trajetória acadêmica e profissional.

Palavras-chave: Desempenho, monitoria, laboratório, química, conceito 


\section{IMPORTÂNCIA DA MONITORIA NA DISCIPLINA DE QUÍMICA EXPERIMENTAL APLICADA À ENGENHARIA: UM ESTUDO DE CASO EM TUCURUÍ/PA}

\section{INTRODUÇÃO}

As Diretrizes Curriculares Nacionais (DCNs), no Art 9ำ, parágrafo 3ํำ da Resolução $N^{\circ} 1$, de 26 de março de 2021, definem que os cursos de engenharia "Devem ser previstas as atividades práticas e de laboratório, tanto para os conteúdos básicos como para os específicos e profissionais, com enfoque e intensidade compatíveis com a habilitação da engenharia, sendo indispensáveis essas atividades nos casos de Física, Química e Informática (BRASIL, 2021).

O ensino da Química Experimental na engenharia civil tem como objetivo a compreensão de conceitos químicos que ocorrem no processo de fabricação, manuseio e utilização dos materiais relacionados à construção civil. Assim, a disciplina é fundamental para que os discentes de graduação consigam analisar e compreender os comportamentos e as mudanças dos materiais presentes nas construções e no dia a dia, dado que a química é definida como a ciência que estuda a microestrutura da matéria, as ligações e as transformações (ALMEIDA; PAIXÃO; CRUZ, 2019).

Dessa maneira, com o intuito de proporcionar aos discentes uma melhor compreensão e aproveitamento dos conteúdos ministrados dentro da disciplina de Química Experimental, enfatiza-se a importância da assistência de monitores. O monitor tem a oportunidade de revisar e aprimorar conteúdos já estudados, além disso, há troca de experiências entre os discentes, ocorrendo o estímulo do trabalho em equipe, a empatia e a solidariedade, além de ajudar o professor no desenvolvimento da didática pedagógica e beneficiando todas as partes envolvidas (professor-monitor-aluno).

Ademais, é perceptível que muitos alunos durante as aulas, tenham dúvidas a respeito do assunto trabalhado. Nesse sentido, vê-se a importância do monitor em sala, que colabora com a turma e seja esse elo entre professor-aluno, a facilitar o entendimento do mesmo. Desta forma, a monitoria nas disciplinas da graduação vai além da aquisição de um título. Essas experiências agregam ao intelecto do monitor, seja na troca de conhecimento com os discentes assistidos ou mesmo com docente orientador (SANTOS; ROCHA; PIRES, 2016).

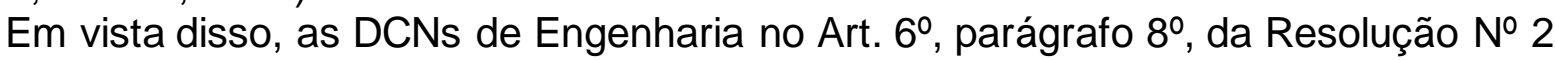
de 24 de abril de 2019, afirmam que no Projeto Pedagógico dos Cursos (PPC) de engenharia devem ser estimuladas várias atividades acadêmicas, entre elas: projetos de extensão, voluntariado, iniciação científica e monitorias. Sendo de significativa importância para o desenvolvimento intelectual, profissional, social e acadêmico dos estudantes (BRASIL, 2019).

Para Schneider (2006) a monitoria tem como objetivo contribuir com o aperfeiçoamento das habilidades pedagógicas dos acadêmicos e, também, auxiliar na compreensão, assimilação e produção do conhecimento. Desse modo, no curso de Engenharia Civil da Universidade Federal do Pará (UFPA), no Campus Universitário de Tucuruí (CAMTUC), observou-se a importância da inserção de alunos monitores na disciplina de química experimental. Visto que, havia a necessidade de um 
acompanhamento mais incisivo nas práticas laboratoriais por questões de segurança, maior entendimento e auxílio na orientação do desenvolvimento do relatório da disciplina.

Diante do exposto, o presente trabalho tem como objetivo destacar a influência do projeto de monitoria desenvolvido na disciplina de Química experimental na turma de Civil 2019.2, a partir disto foi feito uma análise qualitativa, observando e comparando as notas e conceitos da turma na qual houve atuação de monitores, com as notas e conceitos da turma do ano anterior, 2018.2. Visando apresentar a importância da monitoria no desenvolvimento acadêmico dos graduandos de engenharia.

\section{DESENVOLVIMENTO DA MONITORIA}

A monitoria consistiu no acompanhamento de dois monitores presentes na sala de aula juntamente com o professor que ministrou a componente curricular de Química Experimental, durante um período de duas semanas. Desse modo, os monitores e o docente responsável pela disciplina trabalharam em conjunto, proporcionando à turma a ter um acompanhamento mais incisivo durante o período que ambos estavam trabalhando, sendo realizado apoio técnico-científico durante as práticas no laboratório, bem como nas nas práticas experimentais atividades, relatórios e etc, cujos objetivos eram estimular os alunos para obtenção de conhecimento. Como também, sanar as dúvidas durante as aulas, auxiliar nos experimentos laboratoriais e na organização das bancadas do laboratório para receber os alunos, conforme ilustra a Figura 1.

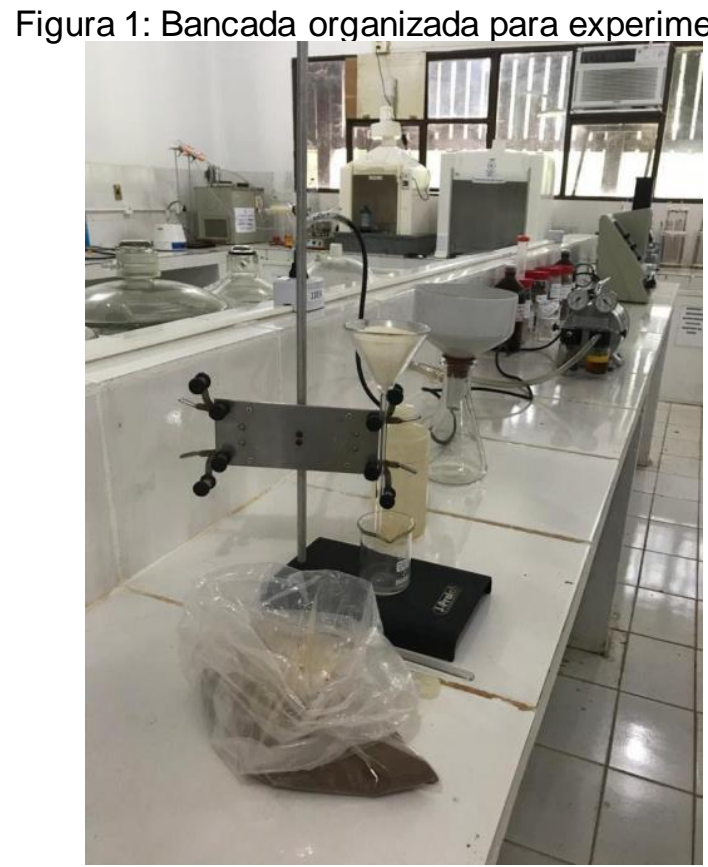

Fonte: Autores (2019).

A monitoria para a disciplina de Química Experimental ocorreu nas dependências do Laboratório de Química - Ensino (LQE), da Universidade Federal do Pará, Campus Tucuruí. O LQE tem significativa importância no CAMTUC, visto que é muito utilizado para práticas experimentais durante o desenvolvimento das disciplinas dos cursos de graduação como, também, para pesquisas referentes a projetos de extensão, iniciação científica, trabalhos de conclusão de curso e pesquisas de pós-graduação.

A seleção dos monitores foi realizada por meio da análise dos conceitos obtidos pelos candidatos nas disciplinas de química teórica e química experimental. Além disso, foi 
verificado o Coeficiente de Rendimento Geral (CRG) dos inscritos e, também, foi revisado o currículo Lattes dos interessados, tais requisitos são de suma importância para essa seleção.

A disciplina de Química Experimental ocorreu do dia 2 ao dia 13 de dezembro de 2019, sendo ofertada para a turma do ano de 2019.2, durante o segundo período do curso, tendo carga horária total de 30 horas. No relato em questão a componente curricular foi ofertada em regime modular, ou seja, com 2 semanas de aulas e sem concomitância com outras disciplinas. Além disso, devido ao espaço físico do laboratório e a quantidade de discentes matriculados na disciplina, houve a divisão da turma em dois grupos, cada um com cerca de 20 discentes, para a execução das práticas experimentais nas dependências do LQE, por isso, foi feita a alternância entre os dias de aula entre os grupos.

Pode-se destacar as principais atividades desenvolvidas pelos monitores durante a disciplina de Química Experimental:

- Organização e limpeza dos materiais e equipamentos;

- Organização das bancadas com equipamentos necessários, separados por equipe;

- Auxílio nas experiências promovidas pela docente, ajudando no manuseio dos equipamentos;

- Esclarecimento dúvidas;

- Leitura do resumo da aula;

- Orientação no desenvolvimento do relatório final da disciplina.

\section{METODOLOGIA}

A metodologia adotada para o presente trabalho, consiste em uma análise comparativa dos conceitos obtidos pelos discentes que fizeram a disciplina no ano de 2019.2 e no ano de 2018.2, cujo intuito é ratificar os benefícios da monitoria para a turma de 2019.2. Nesse contexto, a verificação dos conceitos ocorreu por meio das planilhas de notas finais fornecidas pela docente responsável. Então, para a organização e sistematização dos dados utilizou-se a ferramenta Excel (2010) e logo após foram examinados e discutidos os resultados.

Nessa perspectiva, a universidade utiliza o método de avaliação considerando o conceito obtido pelo discente. A resolução N. 4.399, de 14 de maio de 2013 da UFPA diz que o aluno será aprovado caso obtenha Conceito igual ou superior ao Regular; já para o indicativo de reprovação o conceito será insuficiente ou Sem Frequência, caso não cumpra a carga horária mínima de setenta e cinco por cento (75\%). Para o melhor entendimento quanto aos conceitos e notas da instituição, a Tabela 1 mostra a relação das notas e seus respectivos conceitos.

Tabela 1 - Atribuição do conceito as notas

\begin{tabular}{c|c}
\hline Conceito & Notas \\
\hline Excelente (EXC) & $9,0-10,0$ \\
\hline Bom (BOM) & $7,0-8,9$ \\
\hline Regular (REG) & $5,0-6,9$ \\
\hline Insuficiente (INS) & $0-4,9$ \\
\hline Sem Frequência (SF) & - \\
\hline
\end{tabular}

Fonte: Adaptado de Regulamento do Ensino de Graduação da Universidade Federal do Pará (2013) 


\section{$4 \quad$ RESULTADOS E DISCUSSÕES}

Os resultados alcançados nas turmas de engenharia civil 2018.2 e 2019.2, foram obtidos pela averiguação da quantidade de conceitos finais, sendo 46 discentes matriculados em ambas as turmas. Após isso, conferiu-se o conceito final das duas turmas. Nesse sentido, na comparação de conceitos finais da disciplina, o desempenho das turmas de engenharia civil mostrou resultados diferentes.

Assim, foi observado que a turma de engenharia civil de 2019.2 apresentou o melhor desempenho em relação à turma de engenharia civil de 2018.2. Visto que a turma de 2018.2, representada no Gráfico 1, apresentou as seguintes porcentagens de conceitos finais: $8,7 \%$ de EXC, $69,6 \%$ de BOM, 10,9\% de REG, 6,5\% de INS e 4,3\% de SF. Enquanto a turma de 2019, representada no Gráfico 2, apresentou: 34,8\% de EXC, 56,5\% de BOM e $8,7 \%$ de SF.

Gráfico 1 - Conceitos turma 2018

Conceitos Finais QGE - 2018

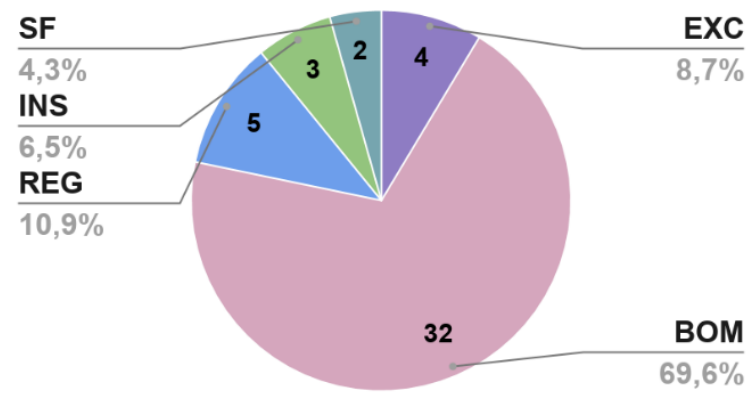

Fonte: Autores (2021)
Gráfico 2 - Conceitos turma 2019

Conceitos Finais QGE - 2019

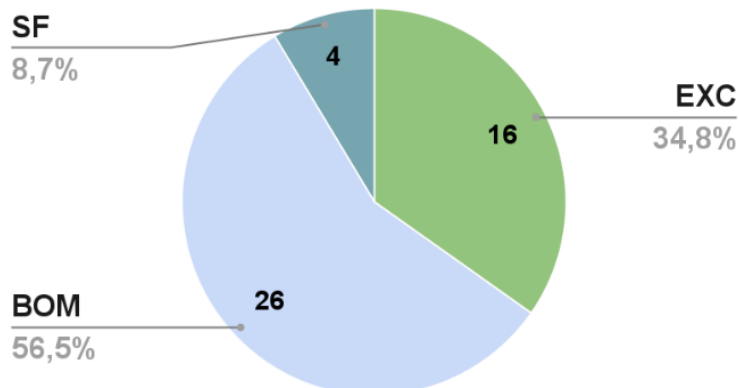

Fonte: Autores (2021)

Averígua-se que esta comparação do nível de desempenho das duas turmas é vista, principalmente, no conceito de EXC, pois na turma de engenharia civil 2018.2, 8,7\% dos discentes atingiram esse conceito. Enquanto que na turma de engenharia civil 2019.2, $34,8 \%$ de discentes atingiram este conceito. Ou seja, o conceito máximo da disciplina foi obtido em maior quantidade na turma de engenharia civil de $2019.2 \mathrm{com} \mathrm{26,1 \%}$ de discentes a mais.

Nesse contexto, no conceito BOM, observa-se uma inversão. Pois, a turma de engenharia civil 2018.2, 69,6\% de discentes da turma atingiram este conceito. Enquanto isso, na turma de engenharia civil $2019.2,56,5 \%$ de discentes da turma atingiram este conceito.

Já nos conceitos de REG e INS, pode-se observar, que os alunos da turma de 2019.2 não obtiveram esses conceitos, sendo o desempenho da turma positivo, pois não houveram notas mínimas e nem reprovações. Enquanto isso, na turma de engenharia civil de 2018.2, $10,9 \%$ de discentes atingiram o conceito REG e 6,5\% de discentes da turma atingiram 0 conceito INS.

Além disso, o índice de evasão na componente, atribuído ao conceito classificado como SF (sem frequência), na turma de engenharia civil 2018.2, foi de 4,3\%, já na turma de engenharia civil 2019.2 foram 8,7\%. O aumento deste percentual é justificado pelo não comparecimento dos discentes às aulas. Os alunos já estavam matriculados na disciplina, no entanto, desistiram do curso antes da ministração da disciplina, não sendo possível o trancamento da matrícula. 
Portanto, torna-se notório o auxílio durante as aulas de laboratório com mais de um monitor para os alunos, para auxiliar nas demonstrações de experimentos como mostrado nas Figuras 2 e 3. Pois, a turma de engenharia civil 2018.2 contou com apenas um monitor durante as aulas, enquanto a turma de engenharia civil $2019.2 \mathrm{com}$ dois monitores. $\mathrm{E}$ concluiu-se, que o nível de desempenho da turma de engenharia civil de 2019.2 foi superior devido a isto. Tais resultados irão refletir em um bom desempenho nas disciplinas futuras do curso, como "Ciência e Engenharia dos Materiais", "Materiais da Construção Civil", "Concreto e Argamassas" e entre outras disciplinas que têm a química como base.

Figura 2: Demonstração do manuseio

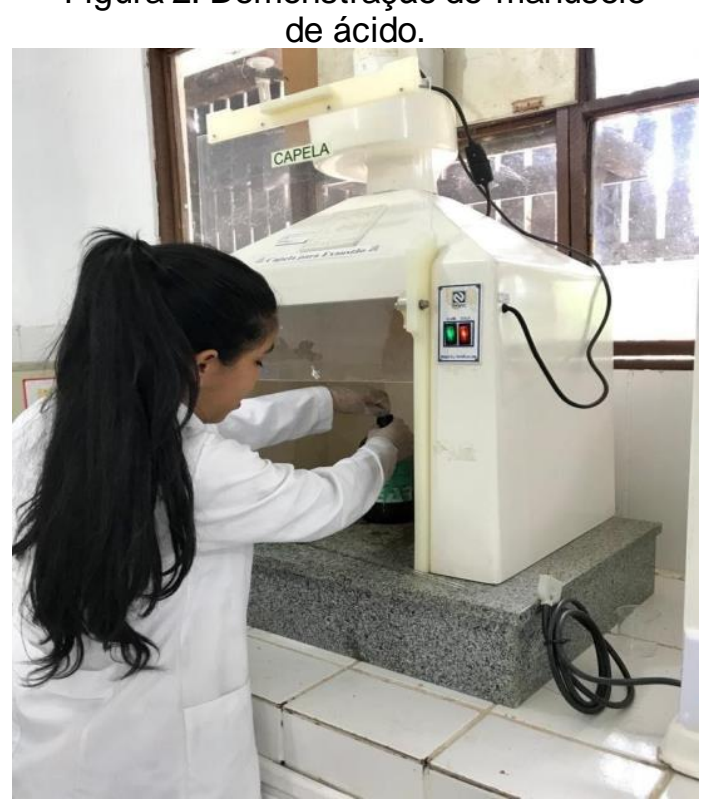

Fonte: Autores (2019).
Figura 3: Apresentação do manuseio de identificadores de ácido.

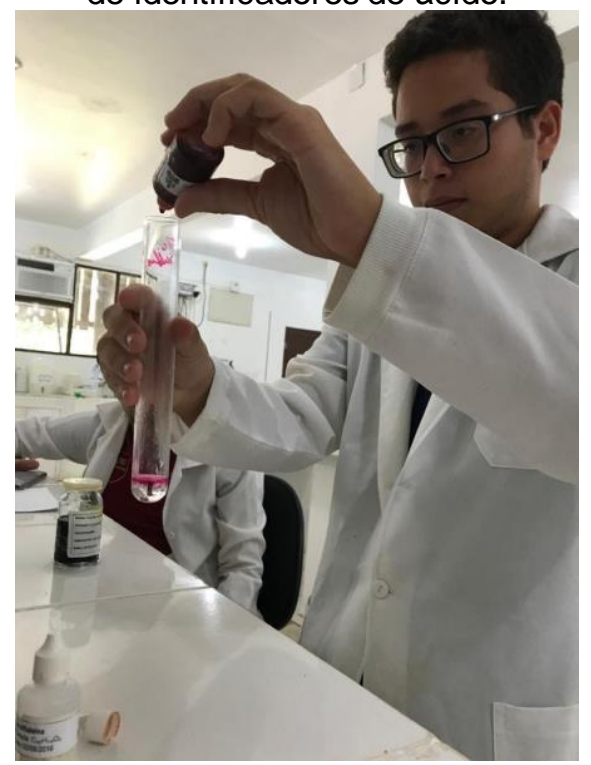

Fonte: Autores (2019

Sendo assim, sabe-se que o acompanhamento durante os experimentos e o esclarecimento de dúvidas, são de suma importância tanto para o aluno como para o monitor. Tendo em vista que as vivências em sala de aula são um incentivo para que os discentes monitores conheçam, desenvolvam habilidades técnicas e profissionalizantes específicas da área de química, como também, sejam incentivados a seguir no ramo da docência. Da mesma forma, os alunos assistidos viram no projeto de monitoria a oportunidade de desenvolvimento acadêmico, demonstrando interesse em, futuramente, desenvolver atividades relacionadas ao ensino-aprendizagem.

\section{CONCLUSÃO}

Dentre os fatores que contribuem para a otimização do desempenho dos discentes na disciplina, pode-se destacar o acompanhamento dos procedimentos experimentais práticos e o auxílio durante atividades da disciplina, sendo proporcionados pelo projeto de monitoria. Diante disso, destaca-se a melhora no desempenho alcançado pela turma de 2019.2, contando com a contribuição de dois monitores durante a realização das aulas de laboratório.

Diante dessa diferença da quantidades de monitores nas duas turmas e de analisar os conceitos de cada aluno para sintetizar em gráficos, pode-se constatar que em média, os conceitos finais de Química Geral Experimental de 2019.2 foi melhor que em 2018.2, em vista da quantidade superior dos conceitos EXC e BOM. 
Portanto, em vista dos pontos abordados e das comparações feitas, conclui-se que os alunos beneficiados pela monitoria em 2019, poderão ter futuramente um aproveitamento superior em futuras disciplinas pertencentes ao curso que tem como fundamento os conceitos da química. Ademais, a monitoria proporcionou aos monitores a possibilidade de desenvolver habilidades no processo de ensino-aprendizagem, contribuindo para uma excelente trajetória acadêmica e profissional.

\section{REFERÊNCIAS}

ALMEIDA, J. L. J.; PAIXÃO, V. V. M.; CRUZ, M. C. P. Concepções dos graduandos do curso de engenharia civil sobre conceitos científicos em química: aprender para intervir. Brazilian Applied Science Review, v. 3, n. 1, p. 515-528, 2019.

BRASIL. Ministério da Educação. Conselho Nacional de Educação. Câmara de educação Superior. Resolução no 1, de 26 de abril de 2021. Institui as Diretrizes Curriculares Nacionais do Curso de Graduação em Engenharia. Brasília, DF: Ministério da Educação, 2021. Disponível em: https://www.in.gov.br/web/dou/-/resolucao-n-1-de-26-de-marco-de2021-310886981 Acesso em: 28 abr. 2021.

BRASIL. Ministério da Educação. Conselho Nacional de Educação. Câmara de Educação Superior. Resolução no 2, de 24 de abril de 2019. Institui as Diretrizes Curriculares Nacionais do Curso de Graduação em Engenharia. 2019. Brasília: Ministério da Educação,2019.

http://portal.mec.gov.br/index.php?option=com docman\&view=download\&alias $=112681$ \%20rces002-19\&category slug=abril-2019-pdf\&ltemid=30192. Acesso em: 28 abr. 2021.

SANTOS, M. E. N. et al. Atuação da monitoria nas aulas de química experimental. Anais I CONAPESC... Campina Grande: Realize Editora, 2016. Disponível em: https://www.editorarealize.com.br/artigo/visualizar/17835. Acesso em: 20 abr. 2021.

SCHNEIDER, M. S. P. S. Monitoria: instrumento para trabalhar com a diversidade de conhecimento em sala de aula. Revista Eletrônica Espaço Acadêmico, v. Mensal, p.65, 2006.

Universidade Federal do Pará (UFPA). Regulamento do Ensino de Graduação da Universidade Federal do Pará.. $2015 . \quad$ Pará, Disponível em: http://www.proeg.ufpa.br/images/Artigos/Academico/Downloads/Regulamento de Graduacao.pdf Acesso em: 02 mai. 2021. 


\title{
THE IMPORTANCE OF THE MONITORING INTHE EXPERIMENTAL CHEMISTRY DISCIPLINE APPLIED TO ENGINEERING: A CASE STUDY IN TUCURUÍ/PA
}

\begin{abstract}
The subject of Experimental Chemistry in the formation of engineering students has a significant importance in combining theory and practice. In this way, this article has the objective of emphasizing the contribution of the monitoring of this curricular component of the Civil Engineering course of the Tucurui Campus UFPA. In this context, a comparative analysis of the concepts obtained by the students of the class of 2018.2 and 2019.2 was developed. Based on the results analyzed, it is highlighted that the students of the class of 2019.2 achieved better performances since they had the help of two monitors during the classes, as a result $34.8 \%$ of the students reached maximum grades and there was no disapproval. On the other hand, in class 2018.2, with just the one monitor, only $8.7 \%$ of the students got the maximum grade in the subject and approximately $11 \%$ failed. Therefore, it can be emphasized the importance of monitoring to support the performance and success of the students of the class, as well as provide the possibility for monitors to develop skills in the teaching-learning process, contributing to their academic and professional trajectory.
\end{abstract}

Keywords: performance, monitoring, laboratory, chemistry, grades. 